\title{
Giant isolated renal cyst hydatid: From diagnosis to treatment
}

\author{
Senol Adanur, Erdem Koç, Tevfik Ziypak, Turgut Yapanoglu, Ozkan Polat \\ Department of Urology, Medical Faculty, Ataturk University, Erzurum, Turkey
}

\begin{abstract}
Summary $\begin{aligned} & \text { Hydatid cyst disease is a parasitic } \\ & \text { infestation caused by Echinococcus }\end{aligned}$ granulosus. Renal involvement is rarely seen as $2-4 \%$ of all cases. Rarely renal involvement is isolated whereas commonly it accompanies involvement of other organs. We aimed to present a 30-year-old male patient with renal involvement reaching a giant size and undiagnosed in another center.
\end{abstract}

KEY wORDS: Hydatid disease; Renal; Nephrectomy.

Submitted 24 March 2014; Accepted 31 May 2014

\section{INTRODUCTION}

Hydatid cyst disease is a parasitic infestation caused by Echinococcus granulosus (1). Echinococcus granulosus may involve any part of the body but the urinary tract involvement is extremely rare (2-4\%) (2). Cyst hydatid disease cannot be diagnosed preoperatively in one out of three patients despite existing serological tests and imaging modalities (3). We aimed to present an isolated hydatid cyst renal involvement that reached giant size and was undiagnosed in another center who referred to our clinic.

\section{Case}

A 31-year-old male patient was admitted to our clinic with the complaint of left flank pain radiating to the back during last 2 months. Patient's past medical history included endoscopic right ureteral stone treatment with right ureteral double-J (DJ) stent placement in another center one month before. Microscopic hematuria and leukocyturia were present at urine analysis of the patient. Creatinine level was $1.2 \mathrm{mg} / \mathrm{dL}$ in biochemical blood tests. Eosinophil ratio was $10.1 \%$ (normal range: 0.9-6) respectively at blood count. A 89 x 144 mm sized septate multicystic mass lesion in the left kiney and grade I hydronephrosis in the right kidney was demonstrated at urinary tract ultrasonography (US). Contrast enhanced computed abdominal tomography (CT) also displayed a 118 x $165 \mathrm{~mm}$ sized hypodense multicystic mass lesion arising from mid-lower pole at the level of the renal pelvis level extending to the anterior and right lateral side and containing septa belonging to daughter vesicles (Figure la-b). The CT scan was negative for cystic lesions in liver, lung and spleen.

Preoperative indirect hemagglutination test was positive. Total nephrectomy was planned and preoperatively albendazole at the daily dose of $400 \mathrm{mg}$ twice daily dose was administered one month before the surgical procedure (Figure 1c-d). No postoperative complication was registered.

\section{Figure 1.}

a. CT view of giant cystic lesion containing septa belongs to the daughter vesicles in the left kidney.

b. $3 D$ volume rendering techniques imaging view of the left renal hydatid cyst.

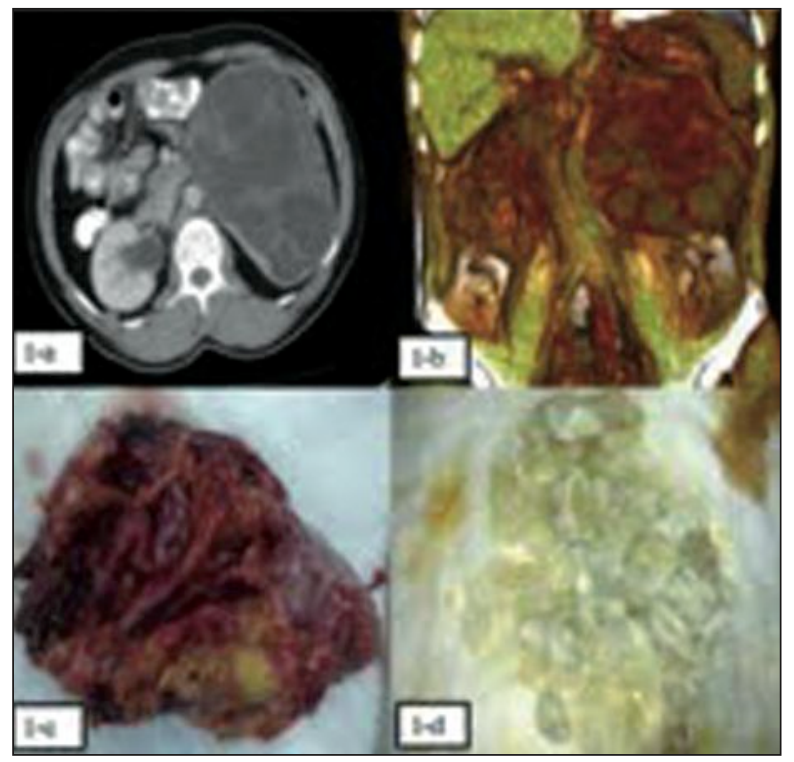

c. Macroscopic appearance of nephrectomy material. d. Macroscopic appearance of daughter vesicles.

\section{Discussion}

Hydatid disease is a parasitic infestation caused by the larval form of Echinococcosis granulosus. The disease is most common in sheep-raising countries including 
Turkey. All parts of the human body are exposed to the disease although liver and lungs are the most common locations. Isolated renal involvement constitutes $2-3 \%$ of all cases (4).

Hydatid cysts rarely affect the renal function. Diagnostic approach includes ultrasonography, KUB radiography or more often by abdomen CT displaying the calcified thick-walled spherical cyst filled with liquid (5).

Serological tests are helpful in diagnosis but they have only $60-90 \%$ sensitivity. Our case was admitted to our clinic due to the increase in the complaint of left flank pain radiating to the back that was related to the undiagnosed left renal hydatid cyst but the history of endoscopic intervention for right ureteral stone one month before. Blood count showed eosinophilia. Contrast enhanced computed abdominal tomography imaging was compatible with giant multicystic isolated renal hydatid cysts with septation by daughter vesicles inside. Serological tests were also positive. Preoperative praziquantel and albendazole treatment for 7 to 10 days is recommended to prevent and minimize cultivation of daughter vesicles if the accidental contamination of operation field occurs (6). We also administered albendazole at the dose of $400 \mathrm{mg}$ twice daily for one month before total nephrectomy in order to minimize the effect of accidental contamination of the operation field in the case of rupture of the giant hydatid cyst by pressure of the surrounding tissue. Surgery is the main treatment modality of renal hydatid cyst disease.

The type of surgical procedure should be decided according to the cyst size, localization, relationship with adjacent tissues and degree of renal parenchymal mass destruction. Simple nephrectomy, partial nephrectomy, endocystectomy plus link closure, pedunculated omentoplasty may be performed. Perioperative albendazole treatment should be given for a reasonable period of time to prevent disease recurrence and anaphylaxis (7). In the present case total nephrectomy was performed but we were anable to remove the cyst en bloc due to its giant size. Nephrectomy was completed after reduction of cyst size by draining daughter vesicles to prevent contamination of the abdomen. Post-operatively medical treatment with albendazole was continued for one month.

Renal hydatidosis has the tendency to slow growing to reach giant size and may cause renal function loss by the compression of the renal parenchyma of the affected renal unit. Although extremely rare, the diagnosis of renal hydatid cyst should be kept in mind in the differential diagnosis especially in endemic areas.

\section{REFERENCES}

1. Schantz PM, Chai J, Craig PS. Epidemiology and control of hydatid disease. In: Thompson RCA, Lymberg AJ, editors. Echinococcus and hydatid disease. Wallingford: CAB International, $1995 ; 233$.

2. Gogus C, Safak M, Baltaci S, Turkolmez K. Isolated renal hydatidosis: experience with 20 cases. J Urol. 2003; 169:186-189.

3. Angulo JC, Sanches-Chapado M, Diego A, et al. Renal echinococcosis: clinical study of 34 cases. J Urol. 1997; 157:787-794.

4. Gögüs O, Bedük Y, Topukçu Z. Renal hydatid disease Br J Urol. $1991 ; 68: 466-469$.

5. Horchani A, Nouira Y, Chtourou M, et al. Retrovesical hydatid disease: a clinical study of 27 cases Eur Urol. 2001; 40:655-60.

6. The Medical Letter, 2010. The Medical Letter: Drugs for parasitic infections. Med Lett Treat Guide 2010; 8:1-13.

7. Unsal A1, Cimentepe E, Dilmen G, et al. An unusual cause of renal colic: hydatiduria. Int J Urol. 2001; 8:319-21.

\section{Correspondence}

Senol Adanur, MD

s.adanur61@hotmail.com

Erdem Koç, MD

Tevfik Ziypak, MD

Turgut Yapanoglu, MD

Ozkan Polat, MD

Department of Urology, Medical Faculty, Ataturk University

25240 Erzurum, Turkey 